\title{
Penerapan Algoritma KNN (K-Nearest Neighbour) Dalam Klasifikasi Data Pinjaman Anggota Koperasi
}

\author{
Deti Fusvita $^{1)}$, Asnawati ${ }^{2)}$, Feri Hari Utami ${ }^{3}{ }^{*}$ \\ Universitas Dehasen Bengkulu Program Studi Sistem Informasi, Fakultas Ilmu Komputer \\ J1. Meranti Raya No.32 Sawah Lebar Bengkulu, Telp. (0736) 22027 \\ asnawati.sopian21@gmail.com, nidokruan@gmail.com
}

\begin{abstract}
Civil Servants Cooperative already uses computers as a means or media in supporting reports making using Microsoft Word and Microsoft Excel applications, so there are still many shortcomings in terms of loan services to cooperative members. Application of loan data classification for members of the Civil Servants Cooperative Seluma Elementary School teachers was made using the Visual Basic Net programming language as a media for making applications and SQL Server 2008 database as a storage medium for processing data. In the process of classifying loan data for cooperative members, the K-Nearest Neighbor (KNN) method has been applied, which emphasizes the results of the process based on the training data patterns that have been made. The training data in question is the data of the previous cooperative members 'loans which will be trend data to determine the data of the members' next loans whether received or rejected. In the classification process, there are 7 (seven) criteria used. The seven criteria will be used as parameters in determining the loan status of cooperative members whether the loan application is accepted or rejected. Based on testing that has been done, the application can provide the results of the classification of members' loan submission data automatically by looking at the final value of each member loan.
\end{abstract}

Keywords: Civil Servants Cooperative, KNN Algorithm, Member Loans, classification

\begin{abstract}
Abstrak
Koperasi Pegawai Negeri sudah menggunakan komputer sebagai sarana atau media dalam pendukung dalam pembuatan laporan dengan menggunakan aplikasi Microsoft Word dan Microsoft Excel, sehingga masih banyak ditemukan kekurangan-kekurangan dalam hal pelayanan pinjaman pada anggota koperasi. Aplikasi klasifikasi data pinjaman anggota Koperasi Pegawai Negeri Guru-guru SD Kecamatan Seluma dibuat menggunakan bahasa pemrograman Visual Basic .Net sebagai media pembuatan aplikasi dan database SQL Server 2008 sebagai media penyimpanan hasil pengolahan data. Dalam proses klasifikasi data pinjaman anggota koperasi telah diterapkan metode $K$-Nearest Neighbour (KNN), dimana metode ini lebih menekankan kepada hasil proses berdasarkan pola data training yang telah dibuat. Data training yang dimaksud adalah data pinjaman anggota koperasi sebelumnya yang akan menjadi trend data untuk menentukan data pinjaman anggota selanjutnya apakah diterima atau ditolak. Dalam proses klasifikasi terdapat 7 (tujuh) kriteria yang digunakan. Ke tujuh kriteria tersebut akan digunakan sebagai parameter dalam menentukan status pinjaman anggota koperasi apakah pengajuan pinjamannya diterima atau ditolak. Berdasarkan pengujian yang telah dilakukan, aplikasi mampu memberikan hasil klasifikasi data pengajuan pinjaman anggota secara otomatis dengan melihat nilai akhir dari masing-masing pinjaman anggota.
\end{abstract}

Kata kunci: Koperasi PNS, Algoritma KNN, Pinjaman Anggota, Klasifikasi

Jurnal Ilmiah Binary STMIK Bina Nusantara Jaya

Vol. 03 No. 01 Tahun 2021, ISSN : 2657-2117 


\section{Pendahuluan}

Teknologi informasi dengan mempengaruhi kemajuan suatu perusahaan untuk mendukung pengambilan keputusan, biaya yang berlebihan, dan birokrasi yang tidak bertanggung jawab. Apabila teknologi informasi ini dimanfaatkan dengan baik maka dapat membantu mengoptimalkan segala aktivitas yang dilakukan dan dibutuhkan oleh perusahaan.

Koperasi Pegawai Negeri Sipil telah menggunakan komputer sebagai sarana atau media dalam mendukung pelaporan dengan menggunakan aplikasi Microsoft Word dan Microsoft Excel, sehingga masih banyak kekurangan dalam pelayanan pinjaman kepada anggota koperasi. Identifikasi masalah sebagaimana dimaksud pada bagian ini mengenai masalah pelayanan usaha pinjaman anggota koperasi. Koperasi memberikan fasilitas pinjaman kepada anggotanya dengan memasukkan persyaratan yang telah ditentukan sebelumnya

Dalam penelitian ini akan dilakukan kajian terhadap data pinjaman anggota koperasi untuk mengklasifikasikan data tersebut melalui kelayakan apakah anggota koperasi layak atau tidak layak pinjaman. Ada beberapa algoritma yang dapat digunakan untuk proses klasifikasi data, salah satunya adalah algoritma K-Nearest Neighbor (K-NN).

Berdasarkan uraian diatas maka penulis tertarik untuk mengangkat judul "Penerapan Algoritma KNN (K-Nearest Neighbor) dalam Klasifikasi Data Pinjaman Anggota Koperasi". Berdasarkan latar belakang diatas maka dapat dirumuskan permasalahan yaitu Bagaimana Implementasi Algoritma KNN (K-Nearest Neighbor) pada Klasifikasi Data Pinjaman Anggota Koperasi.

\section{Tinjauan Pustaka}

Algoritma K-Nearest Neighbor (kadang disebut K-Nearest Neighbor / K-NN) adalah algoritma yang melakukan klasifikasi berdasarkan kedekatan lokasi (jarak) suatu data dengan data lain. Prinsip sederhana yang diadopsi oleh algoritma K-NN adalah bahwa jika seekor hewan berjalan seperti bebek, dukun seperti bebek, dan tampak seperti bebek, maka hewan tersebut adalah bebek [1].

Dalam algoritma K-NN, data dengan dimensi q dapat dihitung jarak dari data tersebut ke data lain. Nilai jarak ini digunakan sebagai nilai kedekatan / kesamaan antara data uji dan data latih. Nilai K pada K-NN berarti $\mathrm{K}$ data terdekat dari data uji. Tetangga Terdekat adalah teknik klasifikasi sederhana, tetapi memiliki hasil kerja yang cukup bagus. Meski begitu, K-NN juga memiliki kelebihan dan kekurangan. Metode penelitian yang digunakan penulis adalah metode Waterfall. Metode waterfall sering juga disebut classic life cycle adalah yang menggambarkan pendekatan sistematis dan sekuensial dalam pengembangan perangkat lunak, dimulai dari spesifikasi kebutuhan pengguna kemudian dilanjutkan melalui tahapan perencanaan, pemodelan, konstruksi[2].

(konstruksi), serta penyampaian sistem kepada pelanggan / pengguna (deployment), yang diakhiri dengan dukungan untuk kelengkapan perangkat lunak yang dihasilkan.

\section{Metodologi Penelitian}

Tahapan metode Waterfall ditunjukkan pada Gambar 3.1 Metode Waterfall

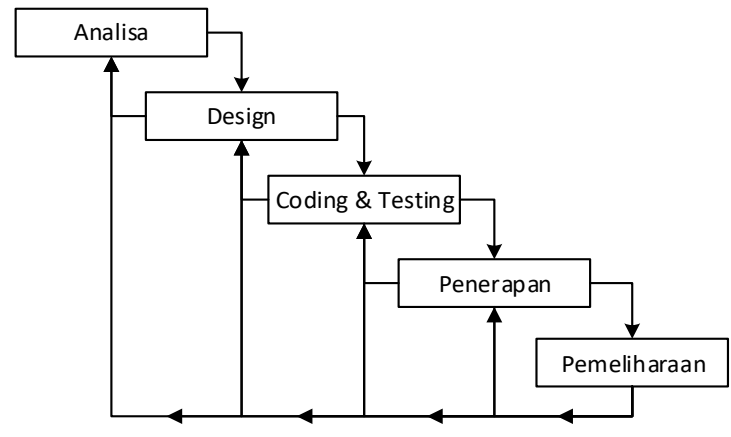

Gambar 3.1. Metode Waterfall

Sistem baru ini dibuat dengan menggunakan Bahasa Pemrograman Visual Basic. Database Net dan SQL Server. Sistem baru ini adalah bertujuan untuk membantu memberikan informasi pola pinjaman anggota koperasi dan dapat digunakan sebagai parameter dalam melakukan peminjaman pinjaman kepada anggota koperasi[3].

Tabel 3.1. Penilaian Syarat Peminjaman

\begin{tabular}{lll}
\hline Syarat Peminjaman & Penilaian & Nilai \\
\hline Permohonan & Ada & 2 \\
\cline { 2 - 3 } & Tidak Ada & 1 \\
\hline surat kuasa & Ada & 2 \\
\cline { 2 - 3 } & Tidak Ada & 1 \\
\hline surat pertanyaan & Ada & 2 \\
\cline { 2 - 3 } & Tidak Ada & 1 \\
\hline \multirow{2}{*}{$\begin{array}{l}\text { Surat kuasa } \\
\text { pemotongan gaji }\end{array}$} & Ada & 2 \\
\cline { 2 - 3 } Fotocopy KTP & Tidak Ada & 1 \\
\cline { 2 - 3 } & Ada & 2 \\
\hline KPN aktif & $>3$ Bulan & 1 \\
\cline { 2 - 3 } & $<3$ Bulan & 1 \\
\hline
\end{tabular}

Klasifikasi yang dilakukan adalah untuk mengetahui apakah pengajuan pinjaman anggota tersebut diterima atau ditolak. Adapun sampel data yang digunakan, seperti tabel 3.2.

Tabel 3.2. Sampel Data Penilaian Pengajuan Pinjaman

\begin{tabular}{|c|c|c|c|c|c|c|c|c|}
\hline $\mathrm{N}$ & Kode & Nama & $S$ & S & S & S & S & \\
\hline o & & & 1 & 2 & 3 & 4 & 5 & 6 \\
\hline
\end{tabular}




\begin{tabular}{|c|c|c|c|c|c|c|c|c|c|c|c|c|c|}
\hline \multirow[t]{2}{*}{2} & \multirow[t]{2}{*}{ P002 } & \multirow[t]{2}{*}{ Marzuki } & \multirow{2}{*}{\multicolumn{5}{|c|}{$\begin{array}{lllll}\checkmark & \checkmark & \checkmark & \checkmark & \checkmark\end{array}$}} & \multirow{2}{*}{\multicolumn{2}{|c|}{$\frac{\geq}{3}$}} & \multicolumn{4}{|c|}{ Tabel 3.7 Parameter $\mathrm{K}=1$} \\
\hline & & & & & & & & & & \multirow[t]{2}{*}{ No. } & Kode & Kode & Distance \\
\hline \multirow[t]{2}{*}{3} & \multirow[t]{2}{*}{$\mathrm{P} 003$} & \multirow[t]{2}{*}{ Desmi Yanteni } & \multirow[t]{2}{*}{$\checkmark$} & \multirow[t]{2}{*}{$\checkmark$} & \multirow[t]{2}{*}{$\checkmark$} & \multirow[t]{2}{*}{$\checkmark$} & \multirow[t]{2}{*}{$\checkmark$} & \multirow{2}{*}{\multicolumn{2}{|c|}{$\begin{array}{ll}\geq & \checkmark \\
3 & \end{array}$}} & & Pinjaman 1 & Pinjaman 2 & \\
\hline & & & & & & & & & & 1 & $\mathrm{P} 004$ & P006 & 0 \\
\hline \multirow[t]{2}{*}{4} & \multirow[t]{2}{*}{ P004 } & \multirow[t]{2}{*}{ Tori } & \multirow[t]{2}{*}{$\checkmark$} & \multirow[t]{2}{*}{$\checkmark$} & \multirow[t]{2}{*}{$\checkmark$} & \multirow[t]{2}{*}{$\checkmark$} & $\checkmark$ & \multirow{2}{*}{$\begin{array}{l}< \\
3\end{array}$} & \multirow[t]{2}{*}{-} & 2 & P001 & P006 & 1 \\
\hline & & & & & & & & & & 3 & $\mathrm{P} 002$ & P006 & 1 \\
\hline \multirow[t]{2}{*}{5} & \multirow[t]{2}{*}{ P005 } & \multirow[t]{2}{*}{ Edi Aprizal } & \multirow[t]{2}{*}{$\checkmark$} & \multirow[t]{2}{*}{$\checkmark$} & \multirow[t]{2}{*}{$\checkmark$} & \multirow{2}{*}{\multicolumn{2}{|c|}{-}} & \multirow{2}{*}{$\frac{\geq}{3}$} & \multirow[t]{2}{*}{-} & 4 & $\mathrm{P} 003$ & P006 & 1 \\
\hline & & & & & & & & & & 5 & P005 & P006 & 3 \\
\hline
\end{tabular}

Adapun Tahapan penyelesaian dari Algoritma K-NN adalah antara lain[4] :

Gunakan kategori mayoritas yang sederhana dari tetangga yang terdekat tersebut sebagai nilai prediksi Menentukan parameter $\mathrm{K}$ = jumlah banyaknya tetangga dari data yang baru terdekat

Parameter $\mathrm{K}=1$ tetangga terdekat.

DFD (Data Flow Diagram) Adapun DFD pada aplikasi Hitung jarak antara data baru dan semua data yang ada klasifikasi data pinjaman anggota Koperasi Pegawai di data training, Untuk menghitung jarak antara data Negeri Guru-guru SD Kecamatan Seluma antara lain : baru dan semua data yang ada menggunakan rumus Euclidean Distance[5][6].

$$
D\left(x_{2}, x_{1}\right)=\left\|x_{2}-x_{1}\right\|_{\cdot 2}=\sqrt{\left.\sum_{j=1}^{p}\left|x_{2 j}-x_{1 j}\right|\right|^{2}}
$$

Tabel 3.5. Hitung Euclidean Distance

\begin{tabular}{llll}
\hline No. & $\begin{array}{l}\text { Kode } \\
\text { Pinjaman 1 }\end{array}$ & $\begin{array}{l}\text { Kode } \\
\text { Pinjaman 2 }\end{array}$ & Distance \\
\hline 1 & P001 & P006 & $\mathbf{1}$ \\
\hline 2 & P002 & P006 & $\mathbf{1}$ \\
\hline 3 & P003 & P006 & $\mathbf{1}$ \\
\hline 4 & P004 & P006 & $\mathbf{0}$ \\
\hline 5 & P005 & P006 & $\mathbf{3}$ \\
\hline
\end{tabular}

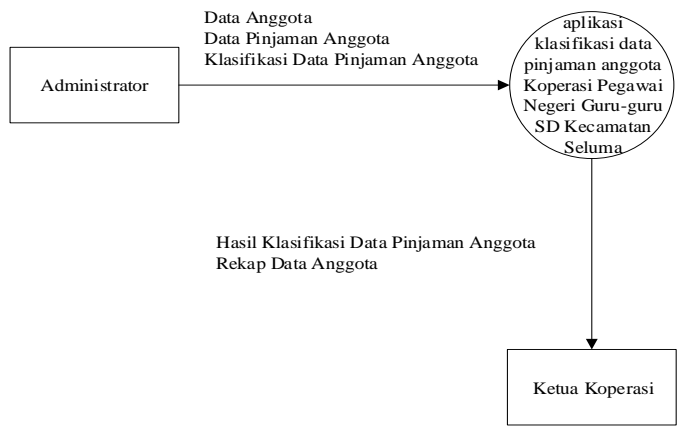

Gambar 3.2. Diagram Konteks

\section{Hasil dan Pembahasan}

Urutkan jarak tersebut dan tentukan tetangga mana yang terdekat berdasarkan jarak minimum ke-K

Aplikasi klasifikasi data pinjaman anggota Koperasi Pegawai Negeri Guru-guru SD Kecamatan Seluma dibuat menggunakan bahasa pemrograman Visual Basic .Net sebagai media pembuatan aplikasi dan

Tabel 3.6. Pengurutan Nilai Distance

\begin{tabular}{llll}
\hline No. & $\begin{array}{l}\text { Kode } \\
\text { Pinjaman 1 }\end{array}$ & $\begin{array}{l}\text { Kode } \\
\text { Pinjaman 2 }\end{array}$ & Distance \\
\hline 1 & P001 & P006 & 1 \\
\hline 2 & P002 & P006 & 1 \\
\hline 3 & P003 & P006 & 1 \\
\hline 4 & P004 & P006 & 0 \\
\hline 5 & P005 & P006 & 3 \\
\hline
\end{tabular}
database SQL Server 2008 sebagai media penyimpanan hasil pengolahan data. Dalam proses klasifikasi data pinjaman anggota koperasi telah diterapkan metode $K$ Nearest Neighbour (KNN), dimana metode ini lebih menekankan kepada hasil proses berdasarkan pola data training yang telah dibuat. Data training yang dimaksud adalah data pinjaman anggota koperasi sebelumnya yang akan menjadi trend data untuk menentukan data Tentukan kategori dari tetangga terdekat Pada tahap ini pinjaman anggota selanjutnya apakah diterima atau akan diambil tetangga terdekat berdasarkan parameter $\mathrm{k}$ ditolak. yang telah ditentukan yaitu 1 , sehingga hasilnya sebagai berikut :

Dalam proses klasifikasi terdapat 7 (tujuh) kriteria yang digunakan. Ke tujuh kriteria tersebut akan digunakan sebagai parameter dalam menentukan status pinjaman anggota koperasi apakah pengajuan pinjamannya diterima atau ditolak[7][8].

Form input data pinjaman anggota koperasi merupakan antarmuka aplikasi yang digunakan untuk mengolah data pengajuan pinjaman anggota koperasi. Dalam proses pengajuan pinjaman koperasi, anggota 
akan dinilai berdasarkan 7 kriteria yang telah 5. Kesimpulan ditetapkan[9]. Adapun form input data pinjaman anggota koperasi terlihat pada Gambar 4.4.

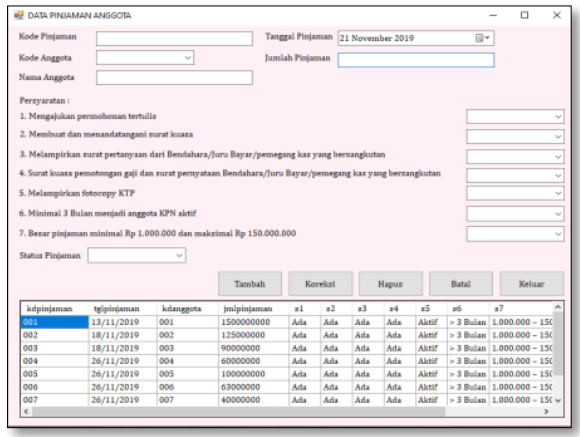

Gambar 4.4. Form Input Data Pinjaman Anggota

Form klasifikasi anggota adalah koperasi merupakan antar muka aplikasi yang digunakan untuk melakukan klasifikasi data berdasarkan data pinjaman anggota koperasi[10]. Adapun form klasifikasi data pinjaman anggota koperasi terlihat pada Gambar 4.5

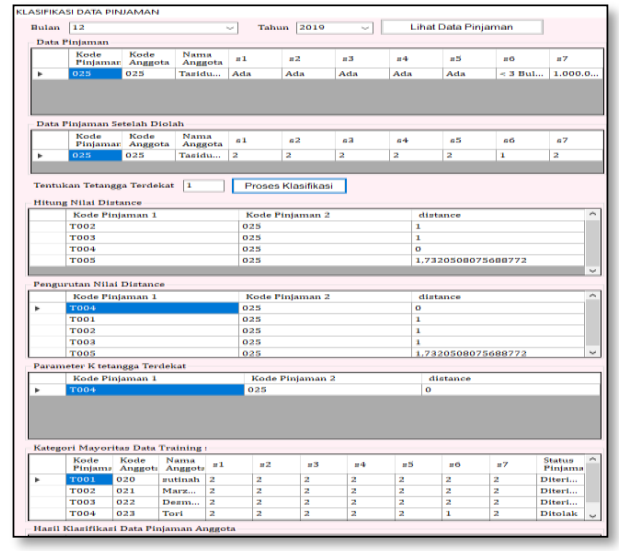

Gambar 4.5. Form Klasifikasi Data Pinjaman Anggota

Output Rekap Data Anggota

Output rekap data anggota akan menampilkan informasi data anggota yang terdapat di Koperasi, seperti Gambar 4.6.

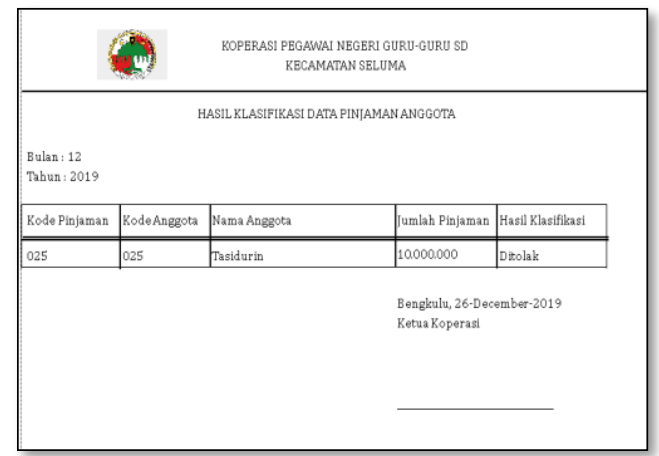

Gambar 4.6. Output Rekap Data Anggota

\subsection{Simpulan}

Berdasarkan hasil dari pembahasan tersebut, maka dapat disimpulkan bahwa :

a. Aplikasi klasifikasi data pinjaman anggota Koperasi Pegawai Negeri Guru-guru SD Kecamatan Seluma dibuat menggunakan bahasa pemrograman Visual Basic .Net sebagai media pembuatan aplikasi dan database SQL Server 2008 sebagai media penyimpanan hasil pengolahan data.

b. Dalam proses klasifikasi data pinjaman anggota koperasi telah diterapkan metode K-Nearest Neighbour (KNN), dimana metode ini lebih menekankan kepada hasil proses berdasarkan pola data training yang telah dibuat. Data training yang dimaksud adalah data pinjaman anggota koperasi sebelumnya yang akan menjadi trend data untuk menentukan data pinjaman anggota selanjutnya apakah diterima atau ditolak.

c. Dalam proses klasifikasi terdapat 7 (tujuh) kriteria yang digunakan. Ke tujuh kriteria tersebut akan digunakan sebagai parameter dalam menentukan status pinjaman anggota koperasi apakah pengajuan pinjamannya diterima atau ditolak.

d. Berdasarkan pengujian yang telah dilakukan, aplikasi mampu memberikan hasil klasifikasi data pengajuan pinjaman anggota secara otomatis dengan melihat nilai akhir dari masing-masing pinjaman anggota

\subsection{Saran}

Berdasarkan penelitian yang telah penulis lakukan di Koperasi Pegawai Negeri Guru-guru SD Kecamatan Seluma, maka penulis menyarankan :

a. Dapat menggunakan aplikasi klasifikasi data pinjaman anggota, agar dapat membantu memberikan informasi apakah pinjaman anggota tersebut diterima atau ditolak.

b. Perlu adanya pengembangan sistem, dengan cara memasukkan data training lebih banyak lagi, agar mendapatkan pola yang lebih akurat dan presisi.

\section{Daftar Rujukan}

[1] Parvin, Hamid. 2008. MKNN: Modified KNearest Neighbor. World Congress on Engineering and Computer Science. USA. San Francisco.

[2] Asri, Romantika Mayang. 2016. Pemodelan System Pakar Untuk Identifikasi Penyakit Pada Tanaman Kedelai Menggunakan Metode Fuzzy K-Nearest Neighbor. S1. Universitas Brawijaya Bertalya. 2009. 
[3] Konsep Data Mining. Tersedia di : https://bertalya.staff.gunadarma.ac.id Diakses 11 Agustus 2019

[4] Tan P, Steinbach M, Kumar V (2006) Introduction to Data Mining. Pearson Education: Boston San Fransisco New York [2] Keller JM, Gray MR, Givens J.A (1985) A Fuzzy K-Nearest Neighbor Algorithm IEEE Transaction on Systems

[5] Mustaqbal, M.Sidi, dkk. 2015. Pengujian Aplikasi Menggunakan Black Box Testing Boundary Value Analysis (Studi Kasus : Aplikasi Prediksi Kelulusan SNMPTN). Jurnal Ilmiah Teknologi Informasi Terapan. ISSN 2407-3911.

[6] Prasetyo, Eko. 2012. Data Mining Konsep dan Aplikasi Menggunakan Matlab. Penerbit Andi : Yogyakarta

[7] Risman, Hendri. Dkk. 2015. Penerapan Metode K-Nearest Neighbor Pada Aplikasi Penentu Penerima Beasiswa Mahasiswa Di STMIK Sinar Nusantara Surakarta. Jurnal Tikomsin ISSN:2338-4018.

[8] Ritayani. 2016. Pengantar Algoritma dan Pemrograman. Jurna.umuslim.ac.id

[9] Sutrisno. 2013. Penerapan Data Mining Pada Penjualan Menggunakan Metode Clustering Studi Kasus PT. Indomarco Palembang. Universitas Bina Darma Palembang.

[10] Sutabri, Tata. 2012. Analisis Sistem Informasi. Penerbit Andi : Yogyakarta 